\title{
Criteria for evaluating synchronous learning management systems: Arguments from the distance language classroom
}

\section{Abstract}

As Virtual Learning Environment (VLE) supported by synchronous technologies such as Synchronous Learning Management Systems (SLMSs) are still new to distance language professionals, criteria guiding the evaluation of the appropriate SLMS for Distance Language Education (DLE) are urgently needed. This article proposes and discusses such criteria. To achieve this, we divide the article into four sections. The first section identifies the need of developing criteria for evaluating an appropriate SLMS for DLE by reviewing what have been achieved in the research into Computer Mediated Communications (CMC) and SLMS. The second section examines established principles of second language (L2) learning and the nature of distance language education in order to establish a theoretical framework for the formulation of such criteria. In section three, we propose five major criteria for evaluating an effective SLMS for DLE. We further discuss and argue for each criterion from the perspectives of both an e-instructor and an e-learner, and drawing on the empirical data from our distance language classroom. The final section acknowledges the limitations of the study and concludes that the proposal of these criteria is timely and that these criteria need to be enriched with the pedagogical and technological developments in DLE.

Keywords: Distance Language Education, Synchronous Learning Management Systems, Synchronous Classroom, Computer Assisted Language Learning, Cyber Face-to-Face Interaction. 


\section{Introduction -The use of CMC and LMS in L2 acquisition}

The term CMC (Computer Mediated Communication) emerged in the early1990s when Internet technology was becoming more mature and sophisticated, and various forms of Internet-based communication tools became available. Wang (2004a) categorizes CMC-based interaction into written, oral and oral-visual interaction. CMC-based written interaction can be supported by text-based communication tools such as emails, discussion forums and text chats (Chun, 1994; Kern 1996; Kitade, 2000; Negretti, 1999; Pellettieri 2000; Smith 2003; Sotillo 2000; Tudini, 2003, 2005), while oral and oral-visual interaction can be achieved through the use of audio and videoconferencing tools (Hampel, 2003; Hampel \& Baber, 2003; Hampel \& Hauck, 2004; Hampel \& Stickler, 2005; Hauck \& Hampel., 2005; Heins et al. 2007; Kötter, Shield \& Stevens, 1999; Kötter, 2001, 2003; Lamy, 2004; Levy \& Kennedy, 2004; Shield, Hauck \& Hewer., 2001; Sykes, 2005, Wang, 2004a, 2004b, 2006, 2007 ). CMC has recently been classified as asynchronous (ACMC) and synchronous CMC (SCMC). Thorne and Payne (2005) have reviewed the history of SCMC in L2 research and its pedagogical possibilities in supporting language learning. It has to be pointed out that one type of CMC tools can only support the development of one or two specific language skills as these technologies are usually standalone tools. For example, emails are employed to improve the learner's writing skills and videoconferencing to assist the development of listening and speaking skills. None of these tools alone can provide a comprehensive platform where the interface between the distance learner and learning context, as defined by White (2003; see discussion in Section 2), can be effectively constructed. Such an interface is precisely what distance language learners urgently need and can only 
be facilitated by a system with a combination of asynchronous and synchronous Internet-based technologies.

Different from standalone CMC tools, an LMS employs a range of information and communication technologies to offer an online platform over the Internet, where a whole course can be planned, facilitated and managed by both the teacher and the learner. Table 1 summarizes the major functions of some of the LMSs available for education purposes ${ }^{1}$.

Table 1 Main functions of current generation of Learning Management Systems (LMS)

\begin{tabular}{|c|c|c|c|c|c|c|c|}
\hline LMS & $\begin{array}{l}\text { Learning } \\
\text { material } \\
\text { management }\end{array}$ & $\begin{array}{l}\text { Discussion } \\
\text { forums }\end{array}$ & $\begin{array}{l}\text { Group } \\
\text { emailing }\end{array}$ & $\begin{array}{l}\text { Audio } \\
\text { confere } \\
\text { ncing }\end{array}$ & $\begin{array}{l}\text { Video } \\
\text { confere } \\
\text { ncing }\end{array}$ & $\begin{array}{l}\text { Text } \\
\text { Chat }\end{array}$ & $\begin{array}{l}\text { Whiteboard \& } \\
\text { synchronous } \\
\text { document sharing }\end{array}$ \\
\hline $3 \mathrm{C}$ & Yes & Yes & Yes & Yes & Yes & Yes & Yes \\
\hline $\begin{array}{l}\text { Blackboard } \\
\text { /WebCT }\end{array}$ & Yes & Yes & Yes & No & No & Yes & No \\
\hline Moodle & Yes & Yes & Yes & No & No & Yes & No \\
\hline
\end{tabular}

As shown in Table 1, LMSs can be roughly classified as asynchronous LMS (ALMS) and synchronous LMS (SLMS). A conventional ALMS (e.g., Blackboard/WebCT and Moodle) provides functionalities mainly to support asynchronous learning activities and resources such as learning materials, discussion forums and group emailing. Although ALMS can also use synchronous tools to support synchronous interaction, it often requires the learner to log in separately for synchronous or asynchronous activities because the two types of functionalities are not seamlessly integrated. An SLMS, such as 3C, however, seamlessly integrates both synchronous and asynchronous tools to support a learning environment which can be accessed with a 
single login account. More importantly, such an environment facilitates synchronous real-time interaction and collaboration via a combination of PC-based conferencing tools such as synchronous document sharing, collaborative whiteboard, text chat and audio and/or video communication.

3C is short for Collaborative Cyber Community and it is the SLMS to be evaluated in this study. It was developed by the National Sun Yat-sen University in Taiwan, and its server presently has a capacity to support up to 500 online asynchronous users and 200 online synchronous users simultaneously. As shown in Table 1, it is the most comprehensive SLMS supporting all the functionalities that the other three can offer. Superior to the other three LMSs, 3C also supports a much needed-dimension in distance language learning, that is, cyber face-to-face interaction via videoconferencing. In other words, $3 \mathrm{C}$ is both a learning management and delivery system facilitating the requirements of a complete course offered online including asynchronously and synchronously. For more discussion on 3C, please see Chen, et al., 2005; Chen and Wang, (in press); Wang and Chen, 2007.

As new online learning environments develop and evolve, it is imperative that they be evaluated in a timely fashion, using a principled approach. This approach needs to be theory-based drawing on the most recent knowledge we have about how learners most effectively learn a language. Doughty and Long (2003: 51\& 67) believe that a "major consideration in the development of distance learning programs is how to make principled choices among technology options”, and these choices need to be "theoretically and empirically motivated, not simply market-driven, as is too often the case”. Developing criteria to help distance language professionals to make informed choices is precisely the focus of this study. 
In what follows, we will review the principles of L2 acquisition and discuss the nature of DLE. The aim of this discussion is to establish a theoretical rationale for the formulation of the criteria to be proposed in this article. We will then move to the core component of the article, the development of a set of criteria for evaluating an appropriate SLMS for DLE. This development will be approached from the perspectives of both an experienced e-instructor and e-learner ${ }^{2}$, and from our understanding of L2 acquisition, the needs of the distance language learner and the pedagogical and technological capabilities of the present generation of SLMSs. Our arguments will be further supported by empirical data from the application of the proposed criteria in our distance programs. It is hoped that this research will provide distance language professionals with some guidelines for evaluating SLMSs, and with some insight into the potentials of the present generation of SLMSs.

\section{A theoretical framework for the proposal of criteria for evaluating SLMS for DLE}

As SLMSs have not been widely employed in language learning, selecting the most appropriate SLMS for distance language learning presents challenges, and needs to be informed by our understanding of established language learning theories and practices, as well as the nature of distance language education and the needs of distance language learners. This section will review SLA theories and the characteristics of DLE in order to establish a theoretical rationale for the development of criteria for evaluating SLMS.

Whatever its drawbacks, the communicative approach has become almost the 
approach in twenty-first century language teaching. Central to this approach is the notion that language is a tool for social communication and interaction. Task-Based Language Teaching (TBLT) is an offshoot of communicative language learning. Motivated by cognitive and interactionist SLA theories and practice, Doughty and Long (2003) define 10 methodological principles (MPs) in TBLT (for TBLT theories and research, see Doughty, 2001; Long, 1996; Long and Robinson 1998, Skehan, 1998), namely,

- $\quad$ use task, not texts, as the unit of analysis;

- $\quad$ promote learning by doing;

- elaborate input (do not simplify; do not rely solely on “authentic” texts);

- provide rich (not impoverished) input;

- encourage inductive (“chunk”) learning;

- focus on form;

- provide negative feedback;

- respect learner “syllabuses”/developmental processes;

- promote cooperative/collaborative learning; and

- provide individualized instruction (according to communicative needs, and psycholinguistically).

These principles are drawn from theories and practices from L2 classrooms where interaction is fact to face. In the implementation of these principles in a distance context, Doughty and Long (2003) emphasize the importance of “compensating for the difficulties posed by the absence of real-time, face-to-face interaction”. However, 
in the evaluation of an appropriate SLMS for distance language learning, we stress the importance of fostering real-time synchronous interaction.

\section{The nature of DLE and the needs of distance language learners}

We believe that in order to adequately address the needs of distance language learners, the formulation of criteria for evaluating an appropriate SLMS should start from an appraisal of the essence of distance language education. Furthermore, as distance language learning provides the context that this research focuses on, it is imperative to clearly state at the outset that this research regards distance education as a distinct field of education that has its own unique and inherent characteristics, significantly different from campus-based education or blended learning. Distance defines the field. We also regard distance language education as a sub-field of distance education. Thus, to a large extent, the nature of distance education reflects the nature of DLE, although the latter has its own features and concerns. The nature of distance education will be examined from both the institutional and the learner's perspectives.

A number of definitions of distance education have been put forward (e.g., Garrison \& Shale, 1987; Holmberg, 1986, 1995; Moore, 1993; Portway \& Lane, 1994). Keegan (1991, 1996) synthesizes these earlier definitions and outlines five major elements of distance learning:

- The quasi-permanent separation of teacher and learner throughout the length of the learning process; this distinguishes it from conventional face-to-face education.

- The influence of an educational organization both in the planning and preparation of learning materials and in the provision of student support services; this 
distinguishes it from private study and teach-yourself programs.

- The use of technical media, print, audio, video or computer, to unite teacher and learner and carry the content of the course.

- The provision of two-way communication so that the student may benefit from or even initiate dialogue; this distinguishes it from other uses of technology in education.

- The quasi-permanent absence of the learning group throughout the length of the learning process so that people are usually taught as individuals and not in groups, with the possibility of occasional meeting for both didactic and socialization purposes.

Although these elements largely describe the nature and development of distance education, they also have some limitations. First, these definitions only apply to distance education up to the 1990s when interaction was defined as primarily asynchronous. Since then, the field of distance education has experienced tremendous developments both in terms of its use of advanced Internet technology and its expanded scope as a result. Real-time synchronous interaction can now be generated not only between the teacher and the learner, but also among learners, and between learners and native speakers anywhere in the world. Thus the term "real-time" should be specified, and “synchronous multi-way interaction” should replace "two-way communication”. Thus the fourth element in Keegan's definition should become “the provision of real-time multi-way interaction so that the student may benefit from or even initiate dialogue”.

Second, Keegan's synthesis approaches distance education from an institutional and a teacher's perspective, and regards distance education as a form of delivery, rather than 
a form of facilitation of education. Consequently, learners and their characteristics do not receive adequate attention.

While Keegan's synthesis of definitions is too generic to encompass the uniqueness of distance language learning, White’s framework focuses specifically on distance language learning rather than distance education in a broad sense. Since distance language learning only started to expand in the last 30 years or so, a comprehensive definition has not been readily found in the literature. White (2006: 248) argues for the importance of defining distance language education from "a synthesis of perspectives including those of teachers, researchers, and learners - reflecting the complete continuum of practices". White (2003: 89) is the first "to provide a theory of distance language learning and also to identify essential aspects of distance language learning”.

White’s $(1999,2003)$ approach complements these previous definitions by placing the learner at the centre of learning when conceptualizing distance education. She (2003) points out:

\footnotetext{
We can think of learners not so much as entering a course or learning environment, but as constructing the course according to the affordances of the learning environment and their own contributions as learners. The challenge for each distance learner is to establish their own effective interface with the learning environment (p. 89). (emphasis in original)
}

Thus, learners should be a defining element in distance education. White (1999) proposed a framework of three dimensions of distance language learning: the individual distance learner, the learning context and the interface between the two.

The learner's dimension comprises the learner's knowledge and skills relating to language learning and distance language learning, and their beliefs and attitudes about distance language learning (White, 2003: 89). The learning context refers to learning 
sources (including the course and other target language sources), learner support, learning spaces, opportunities for interaction, the teacher(s), the distance learning community, features of the learner's immediate learning environment and other resources (White, 2003). The interface is defined by White (2003: 91) as "both the place at which and the means by which learner and context meet, interact and affect one another”. Thus from these definitions it can be seen that learners are the key agents in constructing the interface. White’s (2003: 99) framework stresses the importance of "distance learning as the relationship and interaction between learner and learning context, rather than the delivery of learning materials”. White’s (2003) definition enriches our understanding of distance education by providing us with a different angle from which to perceive the nature of distance education.

We emphasize here that language learning is a skill-based process, rather than a content-based one. Skill developments, such as the acquisition of speaking and listening skills, require constant synchronous interaction in the target language. In other words, the provision of such interaction is a core issue in DLE, and a major indicator of the extent to which the problem of "distance" has been overcome. Thus technology mediated -synchronous interaction should be a distinct feature of distance language learning in the $21^{\text {st }}$ century.

Lastly, "the quasi-permanent absence of the learning group” mentioned by Keegan $(1991,1996)$ in the $5^{\text {th }}$ element of his synthesis is no longer a defining feature of today’s distance learning. Technologies, such as video and data conferencing tools, can adequately support collaborative learning in groups. Learners can cooperate and collaborate in groups both in and outside class. 
Derived from the above discussions, six defining elements of distance language education in the $21^{\text {st }}$ century can be gleaned as follows:

- physical distance from teachers and other learners (Keegan 1996), and possible isolation from the target language community;

- the influence of an educational organization both in teaching and in the provision of student support services (Keegan 1996);

- the use of a combination of technologies and media such as print, audio, video and Internet tools to provide a learning context both synchronously and asynchronously (Wang \& Sun, 2001);

- the provision of multi-way synchronous communication and interaction through media and technology (Wang \& Sun, 2001);

- learners as the key agents of the distance learning process (White 2003);

- the presence of learning groups for collaborative and cooperative learning.

We argue here that these elements, together with the established L2 acquisition theories and practices, should form the theoretical foundations for the criteria for evaluating the appropriate SLMS for distance language learning; an SLMS catering for the above elements is likely to support effective language acquisition at a distance.

\section{The criteria for evaluating the appropriate SLMS for DLE}

We emphasize at the outset that the criteria to be proposed relate to distance language learning rather than to other disciplines in the distance mode. We also stress that these criteria focus on the capabilities of an SLMS to adequately address the challenge that distance language learning faces, that is, the lack of oral and visual interaction. Thus 
we propose that an SLMS should satisfy the following criteria as a minimum requirement for effective distant language learning:

- the provision of asynchronous interaction via multimedia forums;

- the support of cyber face-to-face interaction through an online synchronous classroom;

- the support of small group cyber face-to-face interaction through multiple online synchronous classrooms;

- usability.

The above proposed criteria will be discussed in accordance with L2 learning theories and the needs of distance language learners. These criteria were tested in the evaluation of 3C, the aim being to validate the proposed criteria through an examination of the technological and pedagogical capabilities of 3C in the effective facilitation of synchronous language learning in distance mode. The evaluation took place in two stages. In Stage One, the second author taught a course called "Elearning theories and practices” entirely on 3C from Taiwan with 38 students attending from different parts of the world. The first author attended the course from Australia, for two semesters in 2004 and 2005. In Stage Two, the first author conducted 10 two-hour language tutorials through 3C in late 2005. Seven intermediate Chinese language learners from the Open Learning Chinese program at Griffith University, Australia, participated in these online tutorials. Among them, five lived in different parts of Australia, one in Hong Kong and one in the Czech Republic. They were all adult learners aged between 20-60. Meaning-based tasks for speaking practice were designed and conducted each week. Two types of data will be discussed here. One is the detailed reflection journals completed by the authors after each online session, recording issues such as the use of online tools (e.g., the whiteboard and the 
Joint Web Browser), pedagogical concerns, technical problems if any and the quality of the audio and video. Another source of data is the transcriptions of the video recordings of the online sessions which were recorded using the recording mechanism embedded in 3C. The analysis of the above data is further supported by screen captures of the 3C environment.

\section{The provision of asynchronous interaction}

An ideal SLMS for distance language learning should have both asynchronous and synchronous functionalities that cater for different learner needs and learning strategies. As far as the asynchronous functionalities are concerned, an SLMS should serve as a learning space where cultural and collaborative learning can happen, and where a sense of learning community among the learners can be fostered, thus overcoming the social distance and reducing the isolation. An SLMS can also be an effective platform to provide 'student support services” (Keegan, 1996). It therefore should have the following functionalities as a minimum.

An announcement board (preferably linking to emails)

This function enables the teacher to post announcements on the SLMS. If linked to the emails of learners, the system can send announcements directly to these email boxes. Learners can be notified in a timely manner without having to log into the SLMS.

A multimedia discussion forum

This serves as a collaborative learning space where learners and teachers can post topics and issues for discussion in the target language. An ideal discussion forum for language learning should have the functionality of supporting learning activities, such as creating sound, video or a whiteboard files. Figure 1 illustrates the functionalities of an asynchronous classroom in 3C. It shows that on the left-hand side of the 
platform, there are links to teaching schedule, announcement board, discussion forum, lecture notes, video recorded online tutorials for each lesson, and instructions on how to set up the audio and video communication tool and how to use 3C. The asynchronous classroom can be accessed by both the teacher and the learner at any time. The Announcement and Discussion forums take the same format and are multimedia-based spaces for asynchronous discussions, in the forms of text, audio, video and electronic whiteboard. These forums can be enabled to link to the learner's email box so that each item posted in the forums can also be received by the learner through email. In addition, audio and whiteboard files can be created to facilitate oral and written interaction. For example, the teacher can record a listening exercise and send it to the learner's email box through the Discussion Forum (see Figure 1). These features can be enabled or disabled by the teacher.

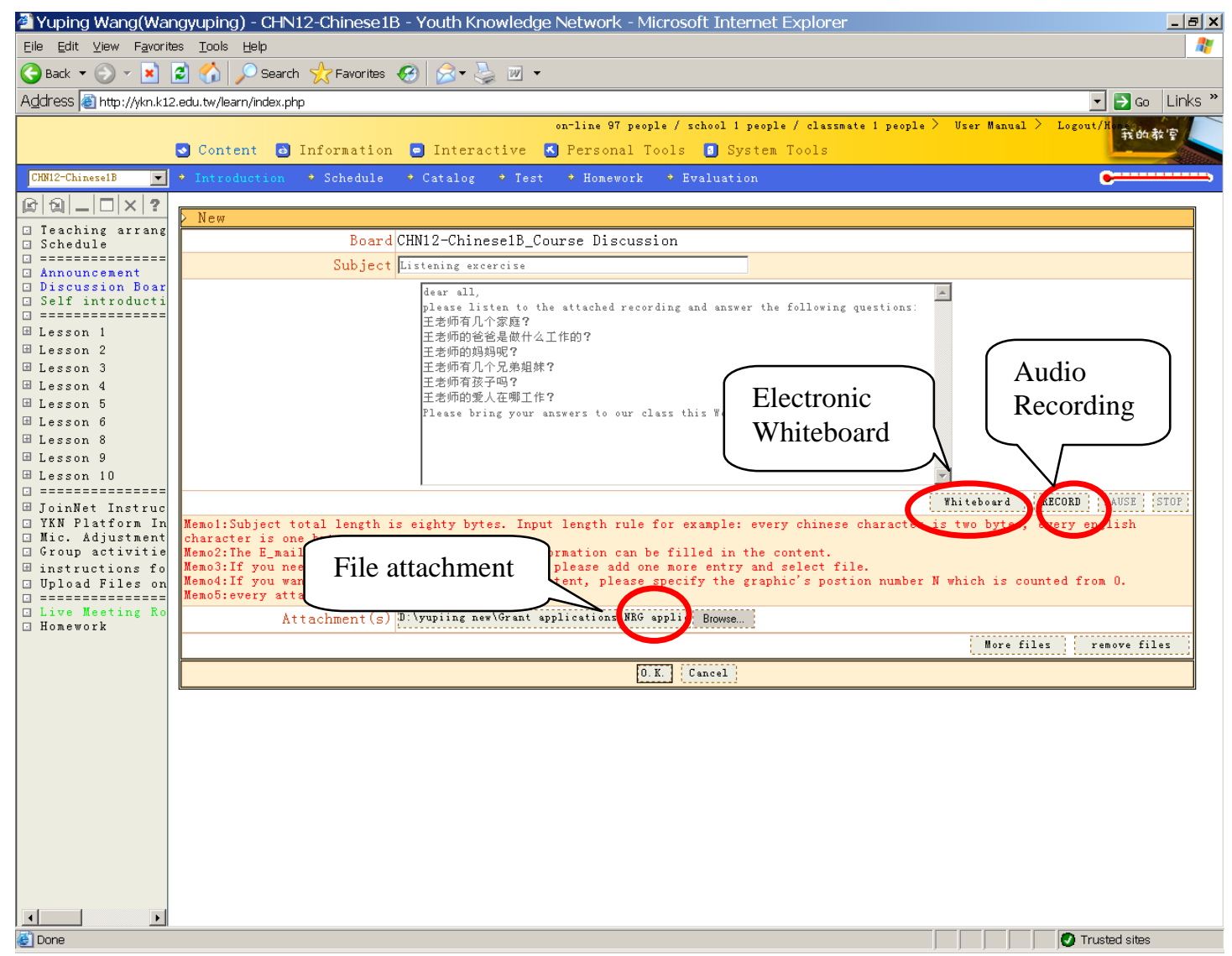


Figure 1 The asynchronous classroom of $3 \mathrm{C}$ and the multimedia discussion forum.

\section{The Teacher's Office}

This function is usually accessed by the teacher for managing the course. This is where the teacher designs the course content and the asynchronous classroom layout, and uploads learning resources, such as lecture notes, assignment items, audio and video files, links to various websites and various instructions. Figure 2 shows that the Teacher's Office in 3C offers a range of functions for the teachers to design and manage the course. Due to the restrictions in length, we cannot discuss all of the functions here. However, the most frequently used functions were course material uploading and learning object link design, both of which were found to be effective and easily managed. Links to learning objects could be moved up or down in the sequence, and could be made visible or hidden.

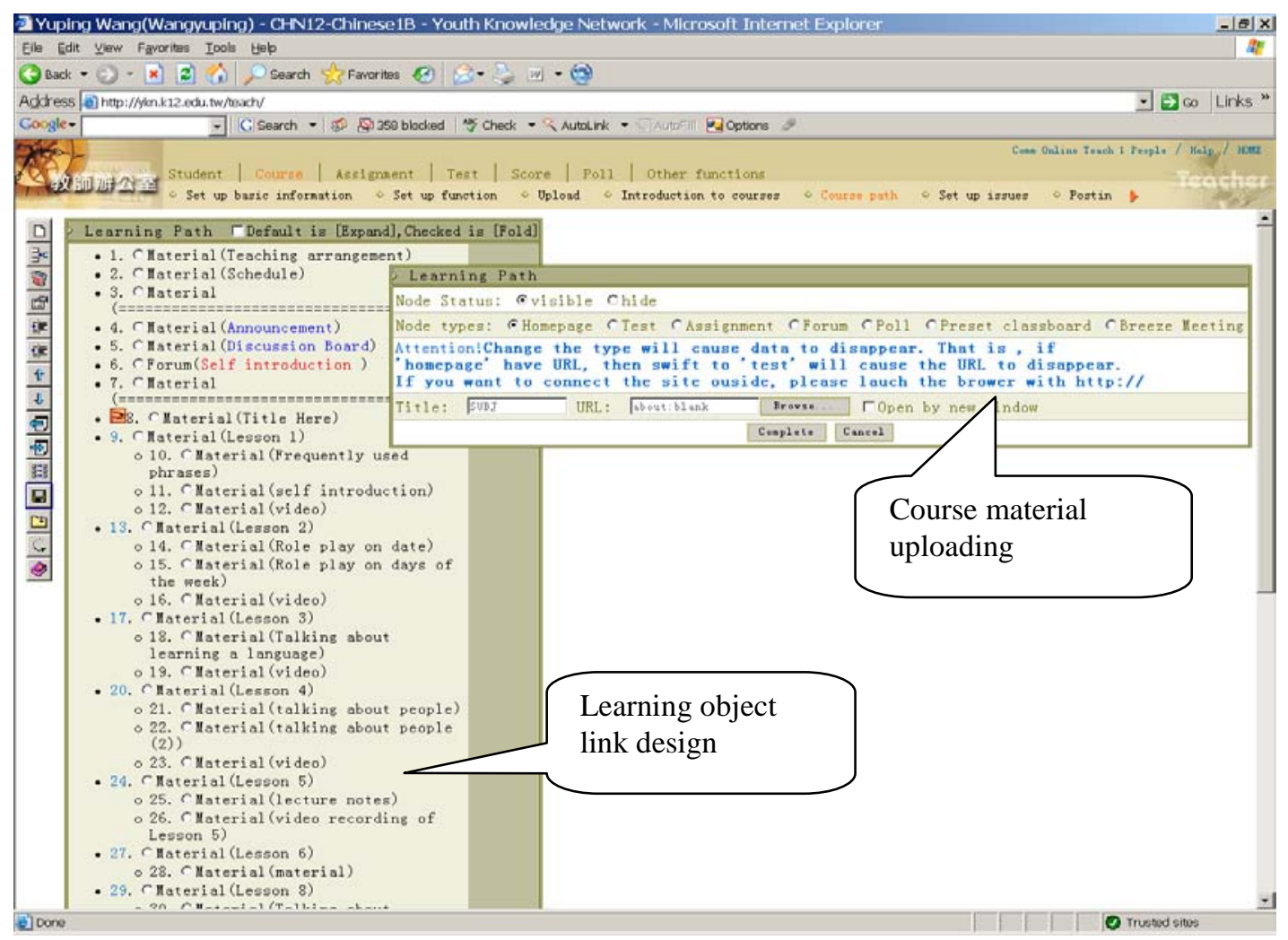


Figure 2 Teacher's Office

The support for the use of a target language

An SLMS for language learning should support the use of the target language in text chat and text-based forums. This is especially valuable for scripted languages such as Chinese and Japanese, as typing and reading in the target language enhances students' memory of the written form of the language. 3C supports the use of English and any other languages installed on the user's computer, through a language preference option which can be changed by individual users. In our cyber face-to-face classes, both Chinese and English were used in the discussion forum and text chats.

\section{The support of cyber face-to-face interaction through an online synchronous classroom}

In view of the special needs of distance language learners, that is, the adequate support of the acquisition of listening and speaking competence, our discussion focuses on the facilitation of online synchronous oral and visual interaction (hereafter cyber face-to-face interaction) with the help of an appropriate SLMS. Unfortunately this is what many LMSs fail to deliver; as such interaction requires more sophisticated technology and higher Internet bandwidth. An ideal SLMS should have a cyber faceto-face classroom supported by an audio and video communication tool and a combination of data conferencing tools. This classroom should serve as a platform where learners can interact with each other and with their teachers orally, visually and in writing, while they are physically apart. Thus it should be supported by the following functionalities:

- a PC-based audio and video communication tool,

- an onscreen whiteboard, 
- synchronous text chat,

- joint web browsing.

An audio and video communication tool supporting quality multi-way oral and visual interaction should be the core component of an effective SLMS for language learning. Multi-way interaction with consistently high sound and video quality usually requires advanced techniques with high data compression rates for transmitting audio, video and images over the Internet. For criteria in relation to the evaluation of the appropriate audio and video communication tools, see Wang (2004b).

In our evaluation of this second criterion - the support of cyber face-to-face interaction, live speaking tutorials were conducted over the Internet in the synchronous classroom supported by a combination of conferencing tools. The multiway oral and visual interaction was supported by JointNet, an audio and video communication tool developed by HomeMeeting and seamlessly integrated into 3C. Through a web camera and a headset, the students and teachers could see and speak to one another simultaneously though they were physically apart. Learners had the option to leave their microphone on all the time during class or turn it off if they did not want to be heard. A variety of learning tasks (e.g., role plays, group presentations, language learning games) were effectively performed and completed in these tutorials. Figure 3 is a screen capture of the online synchronous classroom demonstrating the major components of this environment. Although Figure 3 only shows 3 sub-video windows, up to 18 sub-video windows can be displayed at the same time. 


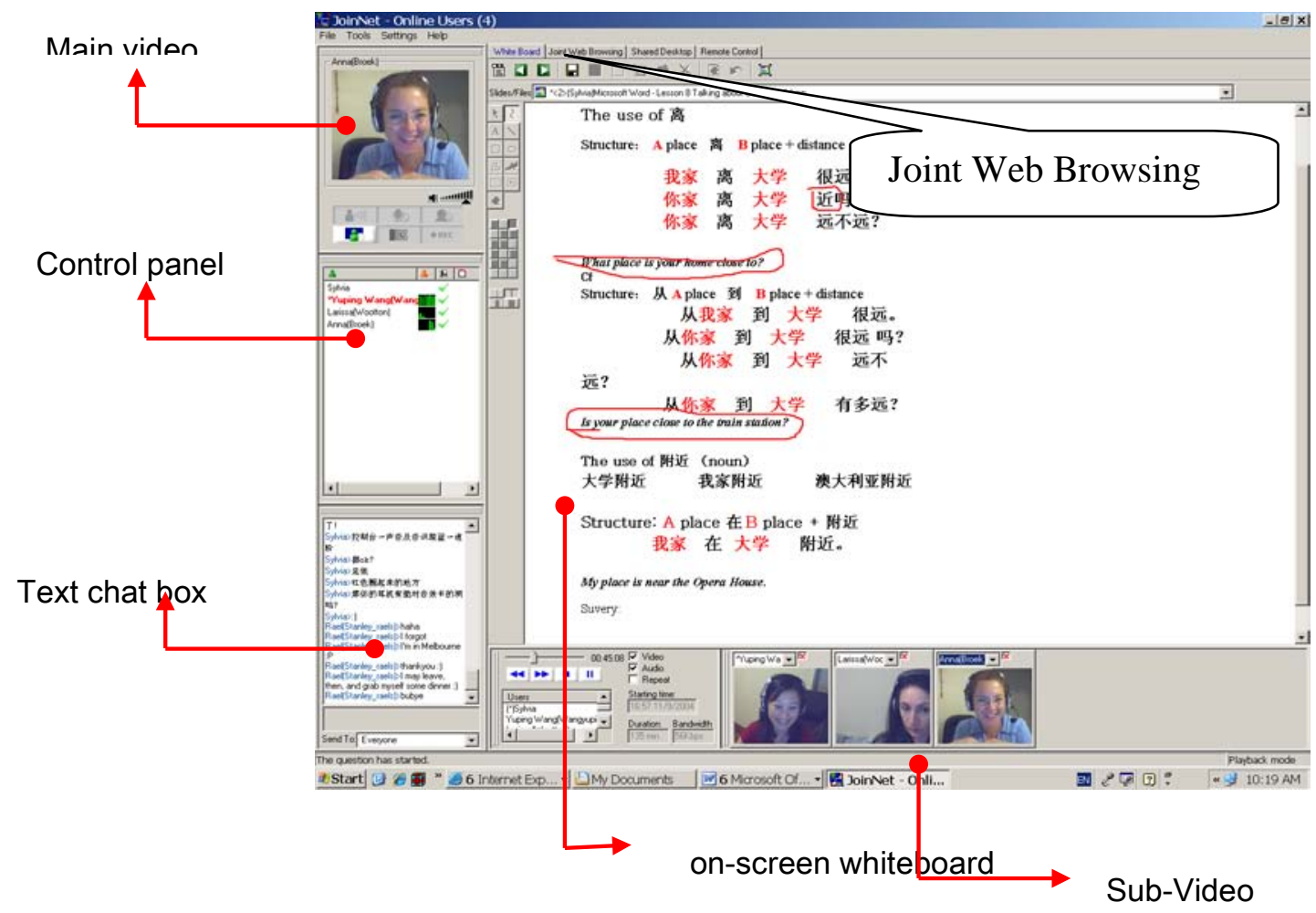

Figure 3 The synchronous classroom with cyber face-to face features in 3C- Session 8

An onscreen whiteboard is another indispensable component of an SLMS as it provides a learning space where negotiation of meaning can happen. Although the concept of the whiteboard comes from the traditional classroom environment, the onscreen whiteboard usually enjoys many advantages over the traditional one. For example, it allows group annotation and collaboration as both the teacher and the learner can write, draw and edit simultaneously. There is no space limitation and its contents can be erased or saved.

As illustrated in Figure 3, the onscreen whiteboard in 3C was placed in the center of the synchronous classroom. Our evaluation of $3 \mathrm{C}$ indicates that this was the most frequently used tool, invaluable for facilitating a variety of language learning activities. Its function to demonstrate prepared documents (e.g., lectures notes, pictures etc.) effectively assisted the organization of teaching before class, and saved 
valuable online time during class, as documents could be uploaded to the whiteboard prior to the start of each lesson. More importantly, it served as a shared learning space where negotiation of meaning took place in an interactive and spontaneous manner as both the teacher and the students could write, type and draw on the whiteboard at the same time, although writing with the mouse could be difficult for new users. Chinese characters could be typed on the whiteboard or written using an electronic writing pad which transmitted the writing directly to the whiteboard. A variety of text colors was used for highlighting the points in either the pre-uploaded documents or joint annotations. The whiteboard contents could be saved or erased entirely or partially.

Synchronous text chat enables instant exchanges of written dialogues between the student and the teacher and among students while attending the online live sessions. This tool is often used as a supplement to the oral and visual interaction in the synchronous class, thus enhancing learner involvement.

Figure 3 also demonstrates that the oral and visual interaction was also supplemented by written messages in the text chat box. Through this function, the students often discussed course-related issues or asked the teacher questions whilst listening to the teacher or other students. The teacher answered questions without having to interrupt the whole class. Symbols were also used in the text chats to represent actions. For example, “papapa” was used to represent applause, e.g., to congratulate a student’s performance -the longer the "papapa", the warmer the applause. Some students typed in Chinese characters and others in English (see Figure 3). Text chat was found to be a great venue for focus on form, negotiation of meaning and individualized learning. 
In order to demonstrate the dynamic interactions that took place when students attended class in this environment, the oral, visual and text exchanges happening simultaneously in the activity contained in Figure 3 were transcribed in Table 2.

Table 2 Session 8 - Talking about distance

\begin{tabular}{|c|c|c|c|c|}
\hline Time & Text chat & Oral interaction & $\begin{array}{l}\text { Visual } \\
\text { interaction }\end{array}$ & $\begin{array}{l}\text { SLMS tools } \\
\text { used }\end{array}$ \\
\hline 43:32 & $\begin{array}{l}\text { TA: 都ok? } \\
\ldots\end{array}$ & $\begin{array}{l}\text { T: How do you say 'what place is } \\
\text { your home close to'? Use the li } \\
\text { structure. }\end{array}$ & $\begin{array}{l}\text { T circles "what } \\
\text { place is your home } \\
\text { close to" on the }\end{array}$ & $\begin{array}{l}\text { Audio (via } \\
\text { Mic/speaker) }\end{array}$ \\
\hline 43:38 & $\begin{array}{l}\text { S4: haha } \\
\text { S4: I forgot } \\
\text { S4: I'm in } \\
\text { Melbourne :P }\end{array}$ & $\begin{array}{l}\text { S2: Um... wojia li, ah, nijia li } \\
\text { shenme difang haha... } \\
\text { (Um, my home from, ah, which } \\
\text { place is your home...) } \\
\text {... }\end{array}$ & $\begin{array}{l}\text { S2 covers her mouth } \\
\text { with her hand. }\end{array}$ & $\begin{array}{l}\text { Visual (via web } \\
\text { camera) } \\
\text { The pointer for } \\
\text { pointing to } \\
\text { items on the }\end{array}$ \\
\hline $43: 45$ & $\begin{array}{l}\text { S4: thankyou :) } \\
\text { S4: I may leave, }\end{array}$ & $\begin{array}{l}\text { T: Yeah, shenme difang (which } \\
\text { place), that's right. }\end{array}$ & S2 laughs. & $\begin{array}{l}\text { lecture note. } \\
\text { The }\end{array}$ \\
\hline $43: 49$ & $\begin{array}{l}\text { then, and grab } \\
\text { myself some }\end{array}$ & S2: OK. & & $\begin{array}{l}\text { Whiteboard } \\
\text { showing the }\end{array}$ \\
\hline $44: 59$ & dinner :) & S2: Ah...close to, um....wo & & lecture notes \\
\hline $\begin{array}{l}\text { 44:01 } \\
44: 07\end{array}$ & S4: bubye & $\begin{array}{l}\text { wangle, duibuqi. } \\
\text { (Ah, close to, um...I forgot. Sorry.) }\end{array}$ & S2 shakes her head & $\begin{array}{l}\text { on talking about } \\
\text { distance. }\end{array}$ \\
\hline & S1: >这 & T: This one, jin. & $\mathbf{T}$ circles the & \\
\hline & TA: bye, all $\wedge \wedge$ & $\begin{array}{l}\text { S2: Ah, just 'jin'. } \\
\text {.. }\end{array}$ & $\begin{array}{l}\text { character for 'jin’. } \\
\text { (see Figure 6) }\end{array}$ & $\begin{array}{l}\text { pen for } \\
\text { highlighting }\end{array}$ \\
\hline $44: 15$ & & $\begin{array}{l}\text { S2: Aha, nijia li shenme difang jin } \\
\text { ma? Ah, just 'jin'. }\end{array}$ & $\begin{array}{l}\text { S2 looks down and } \\
\text { looks up again. }\end{array}$ & $\begin{array}{l}\text { key points on } \\
\text { the Whiteboard }\end{array}$ \\
\hline $44: 16$ & & $\begin{array}{l}\text { (Aha, which place is your home } \\
\text { close to?) }\end{array}$ & & $\begin{array}{l}\text { (see red circles) } \\
\text { Text chat }\end{array}$ \\
\hline $44: 19$ & & T: Yeah. No 'ma', yeah. & T laughs & \\
\hline
\end{tabular}

T: teacher 


\section{S: Student}

\section{TA: Technical Assistant}

As shown in Figure 3 and Table 2, lively classroom interactions happened simultaneously between the students and teacher, in the form of oral, visual and text. This is the type of environment that distance learners would benefit from. Column 4 of Table 2 also shows that the teacher drew the students' attention by highlighting the points on the whiteboard using a pointer. The video windows demonstrated facial expressions (e.g., a shake of head and laughing) and upper body movements (e.g., S2 covering her mouth with her hand and looking up and down). The quality of the video and audio was influenced by many factors, such as the quality of the computer video card and the bandwidth of an individual connection, or even the quality of the web camera. Usually there was no significant delay between the sound and the video transmission if broadband was used. However, with a dial-up connection, both the video and audio quality could be reduced. In this case, we would ask the students to turn off the video in order to ensure good audio quality.

Joint web browsing is another function that an effective SLMS for language learning should embrace. It enables the teacher and learner to browse the Web together during online synchronous classes. Through this tool, the whole class can access web-based materials in the form of text, audio or video contributions. This tool has the potential to foster collaboration, authentic learning and rapport building.

Figure 4 is a screen capture of the whole class viewing a map of Australia on the web. Lively discussions about Australian cities were generated in the target language while students and teacher were looking at the map. The web address of this map was found 
by the teacher before class and pasted in the address bar at the top of the Whiteboard. Through this function, learners could be exposed to extensive authentic input in the form of text, audio or video. For example, the teacher could show the class a short video from Youtube as a catalyst for discussions in the target language or an audio file for a listening exercise from a language website. Joint Web Browsing is thus an ideal tool for promoting target language input and output.

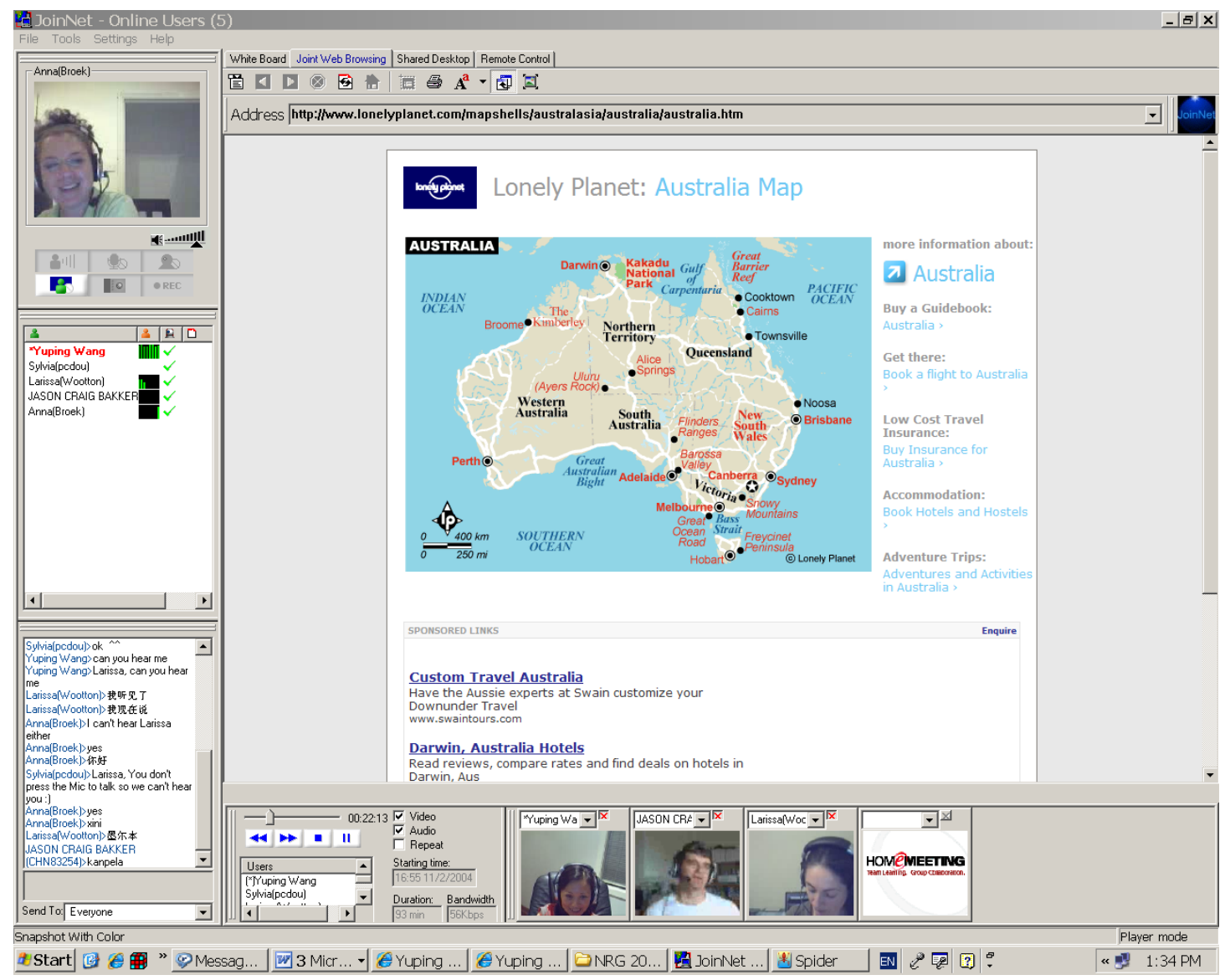

Figure 4 Session 6 on 3C - talking about cities in Australia

\section{The support of small group cyber face-to-face interaction through multiple online synchronous classrooms}

Supporting multiple online synchronous classrooms for each course should form an important feature of an SLMS. This is especially important for language learning as 
TBLT often requires small group activities for task completion. With the same features and functionalities of the online synchronous classroom discussed above, these multiple online synchronous classrooms facilitate group or pair interaction. This function is offered by 3C and was tested in our evaluation of 3C. Usually, following a whole class explanation of the task, students were divided into smaller groups and sent to different synchronous classrooms for group discussions, role plays or dialogue practice in Chinese. The teacher would log into each sub classroom to guide or observe these group activities. Upon completion of the assigned tasks, the students would return to the main classroom for presentation of their group work to the whole class. All the activities in the main and sub classrooms were digitally recorded using the recording tool embedded in 3C. The video recordings of each lesson were then automatically posted in the asynchronous classroom for the participants to review after synchronous classroom sessions or to catch up with classes that they had missed.

\section{Usability}

The criterion evaluating the usability of an SLMS should focus on user friendliness and reliability of the system. This is because the synchronous nature of the LMSs not only requires the user to be competent in managing the system and but also requires the system to run smoothly.

User friendliness here covers two major issues: friendly user-interface design and flexibility in terms of instructional and pedagogical design.

With regard to user-interface design, the three basic principles that should be adhered to are distinct layout, non-specialist language and consistency. Technical jargon and visual overload should be avoided. Some of the guidelines proposed by Graham et al. (2000: 4) are useful here: 
- Standard navigational bars, icons, and links should appear in a consistent location on each page.

- The look and feel of navigational icons should be consistent.

- Organization of group forums should be clear.

In the context of language learning, apart from an interface in English, there should be a function for changing default languages so that users can switch between English and the target language interfaces. An interface in the target language can help create more authentic feel to the learning environment and improve language acquisition through constant visual input. This is particularly beneficial for advanced language learners.

Flexibility in terms of instructional and pedagogical design is an important criterion for evaluating an effective SLMS. An SLMS is likely to succeed if teachers and learners are empowered with a certain degree of control to adapt it to their special needs. For example, teachers should be able to change the layout and sequence of functional menu items provided by the system, and design their own content and layout for the platform to suit the particular needs of their language learning. Certain functions can be enabled for experienced users or disabled temporarily for new users to avoid information overload. As shown in Figures 1 and 3, the interface of 3C is simple and distinct, with navigation bars and icons located consistently on each page. One of the greatest strengths of $3 \mathrm{C}$ is its scalability. The "Teacher's Office" empowers the teacher by giving him/her an effective control over the platform (see Figure 2). In the “Teacher’s Office”, each teacher can design his or her own coursespecific links which appear on the platform of the asynchronous classroom. The links to teaching arrangements, lecture notes etc. on the left-hand side of the asynchronous 
classroom as shown in Figure 2 were created by the teacher. 3C also allows the teacher to enable or disable certain functions. For example, all the forums can be linked to the students' email boxes, but in our evaluation of 3C, this feature was only enabled for the "Announcement Board" so that the students could receive notices in a timely manner. However, this function was disabled in the "Discussion Forum" with the purpose of encouraging the students to log onto 3C regularly and to become familiar with the platform. Furthermore, the user interface can either be in English, or in simplified or full form Chinese characters. We did not use a Chinese interface in our evaluation of $3 \mathrm{C}$ for fear of information overload. Although this platform was not designed and developed specifically for language learning, we found many of its functions (e.g., the audio recording mechanism attached to all forums, video recording of online synchronous classes, the whiteboard attachment to forums, etc.) facilitative to the learning activities we planned for the evaluation of 3C.

Reliability is a crucial issue where technology is involved. As an SLMS incorporates a variety of technologies, many factors are at play. A minimum requirement for an SLMS is stability with a low crash rate. The performance of the SLMS should be constantly monitored, and the system should be upgraded regularly to ensure its stability and reliability.

3C itself proved to be reliable with a zero crash rate during the two-stage evaluation of 3C. Technical problems did occur, but none was directly related to the stability of 3C. It was found to be a very mature system due to the constant maintenance and upgrading by a team of experts who are at the forefront of technological advances. 3C also provided users with information relating to system performance, such as uptime, 
downtime, CPU utilization, disk capacity and network performance. An SLMS with these kinds of information available to the user can assist teachers and educational administrators in making an informed decision in their evaluation of an SLMS. Such information can also help maintain their confidence when they use it.

\section{Conclusion}

Online teaching and learning is expanding rapidly. With so many resources at our disposal, evaluating an appropriate SLMS presents an ongoing challenge to language professionals. In the case of language learning at a distance, the major concern is whether the system is capable of providing quality synchronous oral and visual interaction. This is because such provision is a crucial component of the kind of collaborative learning community advocated by scholars such as White (2006: 260), "where learners find support for and develop control of their learning in interactions and exchanges with peers, learners, teachers and native speakers”. In this article, we have proposed a set of criteria for evaluating an appropriate SLMS for distance language learning. These criteria are proposed in conformity with communicative language learning theories, the nature of distance language learning and the capabilities and potentials of current SLMSs. Our discussion of these criteria supported by empirical data from the distance language classroom indicates, to some extent, that these criteria are adequate for the evaluation of the basic elements of an effective SLMS. At the same time, we also recognize the limitations of this study. Due to the unavailability of similar SLMSs and the sophistication of testing such criteria as the ones proposed in this study, we only tested them with 3C. In-depth testing of other SLMSs would better inform us of the strengths and weaknesses of these criteria. We also recognize that these criteria are not exhaustive, as they are limited to our understanding of the current generation of SLMSs. Consequently, they 
should be improved and enriched in accordance with pedagogical and technological developments in the field.

Nevertheless, the proposal of these criteria is timely, as SLMSs are gaining in importance in today’s education, especially in distance education. It is hoped that these criteria will provide some useful guidance to distance language professionals in their choice of an SLMS, and will help them to be "familiar with the technological options available and their suitability to particular learning goals, and to then implement these technologies capitalizing on their specific features” as advocated by Stockwell (2007:118). In evaluating these criteria, this research also demonstrates what a state-of-the-art learning system can offer to distance language learning. At the same time, the capabilities of such an SLMS present a whole new range of pedagogical issues that need to be further examined by distance language professionals.

\section{Acknowledgement}

This study was partially supported by the National Science Council, Taiwan, under grant NSC95-2520-S-110-001-MY2. 
1 For comparisons of LMSs, please see [http://www.horton.com/html/toolslist.aspx?CatName=Online\%20meeting\%20tools],

[http://www.webconferencing-test.com/site/eng/functions_and_features.html] and

[http://www.communitytechnology.org/products/comparison.html].

2 The first author developed 3C with his team in 1997 and has been using it for teaching since then. The second author is an experienced language teacher who has been using 3C in teaching and research since 2005.

\section{Reference}

Chen, N. S., Ko, H. C., Kinshuk \& Lin, T. (2005). A model for synchronous learning using the Internet. Innovations in Education and Teaching International, 42 (2), 181194.

Chen, N. S \& Wang, Y. (in press) . Testing Principles of Language Learning in a Cyber Face-to-Face Environment. Educational Technology \& Society.

Chun, D. (1994). Using computer networks to facilitate the acquisition of interactive competence. System, 22(1), 17-31.

Doughty, C. (2001). Cognitive underpinnings of focus on form. In P. Robinson (Ed.), Qualitative Research, Theory, Method and Practice (pp. 206-257). Cambridge: Cambridge University Press.

Doughty, C. \& Long, M. H. (2003). Optimal psycholinguistic environments for distance foreign language learning. Language Learning \& Technology, 7(3), 50-80.

Garrison, D. R. \& Shale, D. (1987). Mapping the boundaries of distance education: problems in defining the field. The American Journal of Distance Education, 1(1), 413.

Graham, C., Cagiltay, K., Graner, J., Lim, B.-R. \& Duffy, T. M. (2000). Teaching in a Web Based Distance Learning Environment: An Evaluation Summary Based on Four Courses (CRLT Technical Report 13-00). Bloomington: Indiana University.

Hampel, R. (2003) Theoretical Perspectives and New Practices in Audio-Graphic Conferencing for Language Learning. ReCALL, 15 (1), p 21-36.

Hampel, R. \& Baber, E. (2003). Using Internet-based audio-graphic and video conferencing for language teaching and learning. In U. Felix (Ed.), Language learning on-line: Towards best practice (pp. 171-191). Lisse, The Netherlands: Swets \& Zeitlinger.

Hampel, R. \& Hauck, M. (2004). Towards an effective use of audio conferencing in distance language courses. Language Learning \& Technology, 8(1), 66-82. 
Hampel, R. \& Stickler, U. (2005). New Skills for new classrooms. Training tutors to teach languages online. In CALL (Computer Assisted Language Learning). 18 (4). pp. 311 - 326.

Hauck, M. \& Hampel, R. (2005). The challenges of implementing online tuition in distance language course: Task Design and Tutor Role. In B. Holmberg, M. Shelley \& C. White (Eds.), Distance Education and Languages: Evolution and Change (pp. 258-277). Clevedon: Multilingual Matters Ltd.

Heins, B., Duensing, A., Stickler, U. \& Batstone, C. (2007). Spoken Interaction in online and face-to-face language tutorials. Computer Assisted Language Learning, 20(3), 279-295.

Holmberg, B. (1986). Growth and Structure of Distance Education. London: Croom Helm.

Holmberg, B. (1995). The evolution of the character and practice of distance education. Open Learning, 10(2), 47-53.

Keegan, D. (1991). The study of distance education: Terminology, definition and the field of study. In B. Holmberg \& G. E. Ortner (Eds.), Research into Distance Education/Fernlehre und Fernlehrforschung. Frankfurt am Main: Peter Lang.

Keegan, D. (1996). The Foundations of Distance Education (3rd ed.). London: Croom Helm.

Kern, R. (1996). Computer-mediated communication: Using e-mail exchanges to explore personal histories in two cultures. In M. Warschauer (Ed.), Telecollaboration in Foreign Language Learning (pp. 105-119). Honolulu: University of Hawaii, Second Language Teaching \& Curriculum Centre.

Kitade, K. (2000). L2 learners' discourse and SLA theories in CMC: Collaborative interaction in Internet chat. Computer Assisted Language Learning, 13(2), 143-166.

Kötter, M. (2001). Developing distance language learners' interactive competence Can synchronous audio do the trick? International Journal of Educational Telecommunications, 7(4), 327 - 353.

Kötter, M. (2003). Negotiation of meaning and codeswitching in online tandems. Language Learning and Technology, 7(2), 145-172.

Kötter, M., Shield, L. \& Stevens, A. (1999). Real-time audio and email for fluency: promoting distance language learners' aural and oral skills via the Internet. ReCALL, 11(2), 55-60.

Lamy, M.-N. (2004). Oral conversations online: Redefining oral competence in synchronous environments. ReCALL, 16(2), 520-538. 
Levy, M. \& Kennedy, C. (2004). A task-cycling pedagogy using stimulated reflection and audio-conferencing in foreign language learning. Language Learning \& Technology, 8(2), 50-69.

Long, M. H. (1996). The role of the linguistic environment in second language acquisition. In W. C. Ritchie \& T. K. Bhatia (Eds.), Handbook of Research on Language Acquisition. Vol.2: Second Language Acquisition (pp. 413-468). New York: Academic Press.

Long, M. H. \& Robinson, P. (1998). Focus on form: Theory, research and practice. In C. Doughty \& J. Williams (Eds.), Focus on Form in Classroom Second Language Acquisition (pp. 15-41). Cambridge: Cambridge University Press.

Moore, M. G. (1993). Theory of transactional distance. In D. Keegan (Ed.), Theoretical Principles of Distance Education (pp. 22-38). London; New York: Routledge.

Negretti, R. (1999). Web-based activities and SLA: A conversation analysis research approach. Language Learning \& Technology, 13(1), 75-87. Retrieved June 6, 2004, from http://llt.msu.edu/vol3num1/negretti/index.html

Pellettieri, J. (2000). Negotiation in cyberspace: The role of chatting in the development of grammatical competence. In M. Warschauer \& R. Kern (Eds.), Network-Based Language Teaching: Concepts and Practice (pp. 59-86). Cambridge, England: Cambridge University Press.

Portway, P. \& Lane, C. (1994). Guide to Teleconferencing and Distance Learning. San Ramon Calif.: Applied Business Communications.

Shield, L., Hauck, M. \& Hewer, S. (2001). Talking to strangers -- the role of the tutor in developing target language speaking skills at a distance. In Proceedings of UNTELE 2000, Volume II.

Skehan, P. (1998). A Cognitive Approach to Language Learning. Oxford: Oxford University Press.

Smith, B. (2003). Computer-mediated negotiated interaction: An expanded model. The Modern Language Journal, 87(1), 38-57.

Sotillo, S. M. (2000). Discourse functions and syntactic complexity in synchronous and asynchronous communication. Language Learning and Technology, 4(1), 82-119. Retrieved June 6, 2004, from http://lit.msu.edu/vol4num1/sotillo/default.html

Stockwell, G. (2007). A review of technology choice for teaching for teaching language skills and areas in the CALL literature. ReCALL, 19(2), 105-120.

Sykes, J. (2005). Synchronous CMC and pragmatic development: Effects of oral and written chat. CALICO Journal, 22(3), 399-431. 
Thorne, S. L. \& Payne, J. S. (2005). Evolutionary trajectories, Internet-mediated expression, and language education. CALICO Journal, 22(3), 371-397.

Tudini, V. (2003). Using native speakers in chat. Language Learning and Technology, 7(3), 141-159.

Tudini, V. (2005). Chatlines for beginners: Negotiating conversation at a distance. In B. Holmberg, M. Shelley \& C. White (Eds.), Distance Education and Languages: Evolution and Change (pp. 212-229). Clevedon: Multilingual Matters LTD.

Wang, Y. (2004a). Distance language learning: Interactivity and fourth-generation Internet-based videoconferencing. CALICO Journal, 21(2), 373-395.

Wang, Y. (2004b). Internet-based desktop videoconferencing in supporting synchronous distance language learning. Language Learning \& Technology, 8(3), 90-121.

Wang, Y. (2006). Negotiation of meaning in desktop videoconferencing-supported distance language learning. ReCALL, 18(1), 122-146.

Wang, Y. (2007). Task design in videoconferencing supported distance language learning. CALICO Journal, 24(3), 591-630.

Wang, Y. \& Chen, N. S. (2007). Online synchronous language learning: SLMS over the Internet. Innovate, 3(3). Retrieved May 18, 2007, from http://www.innovateonline.info/index.php?view=article\&id=337

Wang, Y. \& Sun, C. (2001). Internet-based real time language education: towards a fourth generation distance education. CALICO Journal, 18 (3), 539-561.

White, C. (1999). Expectations and emergent beliefs of self-instructed language learners. System: An International Journal of Educational Technology and Applied Linguistics, 27: 443-457.

White, C. (2003). Language Learning in Distance Education. Cambridge: Cambridge University Press.

White, C. (2006). Distance learning of foreign languages. Language Teaching, 39, 247-264. 